\title{
Healthcare at sea: are regulations a guarantee of minimum standards or a barrier to improved practice?
}

\author{
Tim Carter, Sue Stannard
}

Norwegian Centre for Maritime Medicine, Haukeland University Hospital, University of Bergen, Norway

The healthcare of seafarers when distant from onshore expertise has long been an area of concern. Most traditional maritime nations have had regulations in place to ensure that such care can be provided for at least a century, and some for much longer.

Taking the United Kingdom as an early example, schedules of medical stores (medications and medical equipment) were in place from the mid $19^{\text {th }}$ century, and from 1867 there was a statutory requirement to carry a copy of "The Ship Captain's Medical Guide", a publication sanctioned by the maritime authority [1]. Courses of training in first aid for officers became compulsory in the 1900 s and radiomedical services were provided as soon as the technology was available [2]. Distant water ships with over a 100 persons on board were required to carry a doctor from 1894 [3].

All these provisions and more, for example those relating to dangerous cargoes and to large ferries that may have a doctor among the passengers, have been incorporated into international conventions. In ratifying these conventions, maritime states have then been obliged to make appropriate national provisions [4]. This is something which is honoured by most of the traditional maritime states, but rarely met in full by those states in the developing world or by some of the large open registers (flags of convenience).

The globalisation of the maritime industry over recent decades means that seafarers are often serving on ships flagged to a country where national regulation and practice on the management of medical incidents at sea differs from that where they were trained. Hence their training may be incompatible with the medical stores and facilities available or with the requirements and practice of the ship's flag state. They may also be working with officers or crewmembers from other nations who have had training, and therefore expectations, that are different again. The obvious answer to this problem is international standardisation of all the elements of the system for healthcare on board, including training, medical stores and on-board facilities and telemedical assistance. However the discretion granted to signatories to conventions to implement them in their own way makes this a distant dream under the present regulatory arrangements.

The dream is even more distant because of the diversity of conventions and other international initiatives that underpin current arrangements:

- Training in medical first aid and healthcare at sea is compulsory for deck officers and the outline contents of the training course are stated in the International Maritime Organisation requirements associated with their convention on officers' training (STCW) [5]. These were not updated as part of the recent amendments to STCW and are now out-dated and do not reflect good current practice in a number of areas. Even more significant as a barrier to improvement or enhancement of these courses are the arrangements for delivering training. A few countries, like Denmark and Belgium, have a single state-supported provider that provides training to a good standard. Many countries have a commercial market in training, but one subject to a degree of state oversight, however oversight is often by officials who have no knowledge of good remote healthcare practice. Officers required to attend medical courses often regard them as peripheral to their training in navigation and management and so both they and their employers are likely to favour the shortest and cheapest course rather than the best. 
- The medical stores to be carried are not specified in any convention but there are a number of indicative lists produced. These include the list from the World Health Organisation (WHO) included in their publication "The International Medical Guide for Ships" [6]. In the latest edition of this publication the list does not specify the quantities to be carried but quantities were included in a more recent addendum to the "Guide" [7]. The political context within which WHO works means that this list is based on existing lists of medications approved by the WHO and on medical equipment specified for use in emergencies by UN Agencies. This has the result of excluding optimal remedies for common but non-life-threatening conditions that arise at sea and disable crewmembers, notably seasickness [8]. There are a number of national schedules, which differ from one another. For countries in the European Union there is a Directive specifying the generic groups of medications that must be carried and their quantities [9].

- As noted, the WHO publishes "The International Medical Guide for Ships", now in its $4^{\text {th }}$ edition. Concerns have been expressed about whether this book adequately meets the needs of those managing illness and injury at sea, but there are no plans or budget to revise and update it. Several traditional maritime nations produce their own national guides, varying in size, the degree of detail given and in the style of presentation [10-13]. They generally relate more closely to the training and medical stores requirements in their countries of origin than do any of the international guides or lists, but this means that seafarers trained elsewhere may have to relearn their practices and approaches to meet the requirements of the flag of the ship on which they are serving. A number of the countries that still produce their own guides would welcome a good international alternative, but here again minor differences in national practice, for instance whether or not cardiac defibrillators are provided on board or whether seafarers are trained in techniques for giving intravenous therapy, can be barriers to common approaches.

- Provision of telemedical advice to ships is an obligation placed on maritime states that ratify the International Labour Organisation Maritime Labour Convention, 2006 [14-16]. However the reality is that, while the traditional maritime nations do provide such services, normally freely available for use by ships of all nations (and Italy has long provided a service that is identified as an international one), few developing world countries do so. Equally it is not a feature of the support provided by the major open registries for their large fleets. A consequence can be that ships flagged to those countries that do not have services may either fail to obtain advice when needed or freeload on the services of other nations. The scope of national provisions varies widely: in some cases an obligation is put on ship operators to make private provision; a number of countries provide services linked to their coastguard and search and rescue facilities that are primarily concerned with the management and evacuation of the seriously ill or injured, whereas others additionally provide direct access by seafarers to confidential clinical advice. One of the major problems can be language difficulties between ship and Telemedical Advisory Service (TMAS), as medical terms do not form part of standard maritime English. Most services rely on voice and email communication and, except in the cruise industry and in some marine work in very remote locations, the enhanced communications capability offered by maritime satellite broadband, for instance use of video and transmission of real time clinical measurements, has not been developed [17].

While it is easy to produce a critique of current arrangements it is important to recognise that the current legally based requirements do ensure that even the least concerned ship operator and maritime authority has some basic systems for the management of medical emergencies at sea in place. This may not be done for altruistic reasons, but the threat of port state control inspections or flag state inspections identifying non-conformities and applying sanctions that can be costly in ship operating terms should encourage compliance. The downside of this argument is that having such a legally based framework in place all too readily means that there is little incentive for even the well-intentioned ship owner to do more than the minimum. The reality also is that, as so many aspects of the provisions for seafarer medical care are outside the ship operator's direct control, there is a limit to what they can do, unless they develop entirely complementary arrangements covering training, facilities and equipment, on board procedures and expert onshore TMAS.

The extent of regulation in the maritime sector is in contrast to the position in other sectors that operate in remote areas far from medical care facilities, such as scientific and other expeditions, the military, mineral prospecting and mining companies and the energy industries. All of these sectors take a much more active approach to remote healthcare and are receptive to new innovations, not least because they see the reputational importance of, and an economic imperative for, good management of medical emergencies, that is often lacking in the maritime sector.

Some key questions have to be addressed before looking at whether and how to improve the management of medical events at sea.

1. What types of event occur and what is their relative frequency? 
2. Given that minor, temporarily disabling, but not life-threatening events, are common while major and life-threatening ones are rare, how can arrangements be developed that cover both in an equitable way?

3. How do ethics interact with practicability and cost, for instance should training and equipment enable very rare events to be managed to the best standards or should the focus be on optimum responses to a limited range of common/serious conditions?

4. What are the inherent limitations on competence, even with optimal training, for those who only rarely have to manage a serious incident?

5. What are the inherent limitations on the provision of emergency healthcare on board, even with optimum facilities and equipment?

6. How big would the benefits be, and to whom, from optimising the arrangements for healthcare on board?

7. What costs would this involve and what savings could be made?

8. What scope is there for pilot studies, perhaps at national level or within a single company, to evaluate these benefits and costs?

9. How could new approaches to healthcare at sea be developed and implemented?

10. How could an international consensus on the need to progressively modify current approaches to ensure better healthcare at sea be developed?

11. How could international conventions and other instruments be modified to take account of this, and how long a time period would be needed?

These are all large and complex questions, and many do not have clear answers. For instance, it is apparent that there is very little good information on the frequency of different sorts of medical event arising at sea or on their outcome. A kaleidoscopic picture can be built up from sources such as ship medical logs, use of medications, contacts with TMAS, emergency evacuations and repatriations and deaths at sea [18]. What is clear, however, is that the current arrangements, based on national regulations aligned with international conventions do not appear to be working well and this begs one further question: are there new and different approaches that could be adopted and which could overcome some or all of the current difficulties?

One such approach, which would be new to the maritime sector, but which has been widely used elsewhere, would be to base the totality of the management of medical events at sea within a framework of care pathways that reflect good practice and could replace the current medical guides. These in turn would then be used to determine training, medical stores and facilities, as well as the specification for TMAS.

Care pathways are, in essence, sequential decision trees or algorithms. They start with the presenting signs or symptoms and, by asking further questions, progressively work through to the most probable causes of the problem and then indicate the degree of urgency needed in treatment, any warning signs to look out for and the care plan to be adopted. They are widely used in clinical practice and their effectiveness has been validated $[19,20]$. Use is most common in North America, Australasia and Britain, from where most of the following examples are drawn. They are increasingly being used in situations where those without full medical training have to take important decisions on early care. Examples of users include emergency paramedics and ambulance crews, the military during deployments, those providing emergency care at remote locations and health staff with limited training in rural areas of developing countries [21, 22]. They also form the background for many tools to help those with symptoms decide on their own healthcare needs [23].

Developing a set of such pathways for use in a maritime setting would be challenging as there could be endless debates about priorities, diagnostics and treatments, but there may well be scope for learning, or even copying from those already in use that are relevant. In reality much of the content of such pathways is already specified in a range of different ways in national and international ship medical guides. One consequence of the adoption of care pathways would be much clearer specification of the competencies needed by those responsible for healthcare on board, thus they could form the basis for revised training arrangements that could be more internationally consistent. Similarly pathways would identify the medications and medical equipment needed and so could lead to schedules for medical stores that were standardised. At certain points the need to consult with TMAS would be noted and the information that needs to be collected and shared with their advisers listed. This could simplify communications and open the way for better quality advisory support.

Care pathways lend themselves to presentation in a variety of formats, on paper; preloaded on to portable IT devices, where each step can be seen separately and where there could be facilities for recording and storing clinical measurements and related records, or on a web server. With the web option the decision points, actions taken and measurement data could also be accessible to any TMAS consulted.

This is not solely an issue for maritime health professionals, it is one for the whole maritime sector. As a first stage a consensus is needed among maritime health professionals, and an International Maritime Health Association workshop on the topic is taking place in early 2015. If there is agreement that this is a viable approach, further work could then be undertaken, subject to funding being available. A series of care pathways could be developed, initially as guides to good practice, but later with a view to incorporating them into more formal documents such 
as ship medical guides. In turn these can be the source of detailed information on associated requirements and can be used to drive a modernising agenda on the medical training of officers, as well as for specifying the medicines, medical equipment and on-board facilities needed. They can also be used to indicate how those managing medical incidents at sea can best interact with onshore TMAS. This process could be seen as long and ambitious, but are there any viable alternative ways to improve both the regulation and practice of medical care at sea?

\section{REFERENCES}

1. 1867 Merchant Shipping Act. See also Carter T. Merchant Seamen's Health 1867-1969: Medicine, Technology, Shipowners and the State in Britain. The Boydell Press, Woodbridge 2014: 32-33, 53-57.

2. Carter T. Merchant Seamen's Health. The Boydell Press, Woodbridge 2014: 64-65.

3. 1894 Merchant Shipping Act. See also Carter T. Merchant Seamen's Health. The Boydell Press, Woodbridge 2014: 51-52.

4. Medical First Aid Guide, International Maritime Dangerous Goods Code (Supplement 2010). International Maritime Organisation, London 2010.

5. Elementary First Aid (IMO Model Course 1.13) STCW A-VI/1-3, Medical First Aid (IMO Model Course 1.14) STCW A-VI/4-1, Medical Care Person In charge Course (IMO Model Course 1.15) STCW A-VI/4-2. International Convention on Standards of Training, Certification and Watchkeeping for Seafarers (1978) - as amended. International Maritime Organisation. London 2010.

6. International Medical Guide for Ships. $3^{\text {rd }}$ Ed. World Health Organisation, Geneva 2007.

7. Quantification Addendum: International Medical Guide for Ships. $3^{\text {rd }}$ Ed. World Health Organisation, Geneva 2010.

8. IMHA Workshop, Athens 14-15 November 2008. The ship's medical chest. http://imha.net/images/stories/IMHA\%20medical\%20 chest\%20workshop\%20Athens\%20Final\%20report.pdf (Accessed 29 September 2014).
9. Council Directive 92/29/EEC of 31 March 1992 on the minimum safety and health requirements for improved medical treatment on board vessels. EEC Council of Ministers.

10. Schreiner A, Aanderud L eds. Medicine on Board. Fagbokforlaget, Bergen, Norway 2008.

11. Ebert H, Schepers B-F eds. German Medical Guide for Ships: manual for Captains and Ship's Officers. Dingwort, Hamburg 2008.

12. The Ship Captain's Medical Guide. $22^{\text {nd }}$ Ed. The Stationery Office, London 1999.

13. Kirk E ed. The Maritime Medical Manual. Danish Maritime Authority/ Iver C Wielbach, 1998.

14. International Convention for the Safety of Life at Sea (SOLAS) 1974 (IMO)/IAMSAR Manual I, II, III / INMARSAT Convention.

15. International Convention on Maritime Search and Rescue (1979) SAR Convention (IMO).

16. Maritime Labour Convention, 2006 (MLC 2006) (ILO) A 4.1, 4(d.).

17. IMHA/NCMM workshop, Malta, February 2013 Maritime telemedicine - state of the art: Consensus. http://www.imha.net/images/ stories/2013-02WS-MALTA-TELE-consensus-paper.pdf (Accessed 29 September 2014).

18. Carter T. Mapping the knowledge base for maritime health: 3 illness and injury in seafarers. Int Marit Health 2011; 62: 224-235.

19. NICE Pathways - mapping our guidance, 2014. http://pathways. nice.org.uk/.

20. Rotter T, Kinsman L, James EL et al. Clinical pathways: effects on professional practice, patient outcomes, length of stay and hospital costs. Cochrane Collaboration, 2010. http://apps.who.int/rhl/ reviews/CD006632.pdf (Accessed 2 October 2014).

21. Paramedic Pathfinder and Community Care Pathways. North West Ambulance Service. (UK) undated. https://www.whatdotheyknow. com/request/181304/response/449166/attach/3/Pathways.pdf (Accessed 2 October 2014).

22. Clinical Guidelines for Operations, Joint Services Publications, JSP 999, 2012. https://www.gov.uk/government/uploads/system/ uploads/attachment_data/file/79106/20121204-8-AVB-CGO_Online_2012.pdf (Accessed 2 October 2014).

23. NHS Choices, Symptom Checker. https://www.nhs.uk/symptomcheckers/pages/symptoms.aspx (Accessed 2 October 2014). 